\title{
Spectrophotometric Determination of Cu(II) in Analytical Sample Using a New Chromogenic Reagent (HPEDN)
}

\author{
Esraa Raafid ${ }^{1}$, Muneer A. Al-Da'amy ${ }^{1}$, and Salih Hadi Kadhim ${ }^{2, *}$ \\ ${ }^{1}$ Department of Chemistry, College of Education for Pure Science, University of Kerbala, Kerbala, Iraq \\ ${ }^{2}$ Department of Chemistry, College of Science, University of Babylon, Babylon, Iraq
}

*Corresponding author:

email: hadi197019@yahoo.com

Received: July 19, 2019

Accepted: September 12, 2019

DOI: $10.22146 / \mathrm{ijc} .47894$

\begin{abstract}
A sensitive, accurate and rapid spectrophotometric method that can be used for the determination of $\mathrm{Cu}(\mathrm{II})$ in analytical samples using a new chromogenic reagent azo-Schiff base 1-((4-(1-(2-hydroxyphenylimino)ethyl)-phenyl)diazenyl) naphthalene-2ol (HPEDN) was studied. The synthesized new (azo-Schiff base) ligand was complexed with copper(II) and characterized using UV/Vis spectroscopy, IR spectra, ${ }^{1} \mathrm{H}-\mathrm{NMR}$, ${ }^{13} \mathrm{C}-\mathrm{NMR}$ spectra, Molar electrical connectivity, and measuring of their melting points. The obtained complex showed a brown color with maximum absorption at $\lambda_{\max }=500 \mathrm{~nm}$ at $\mathrm{pH}=9$. Beer's law was obeyed in the concentration range of 1.7 to $5.4 \mu \mathrm{g} / \mathrm{mL}$. The molar absorption and Sandell's sensitivity values of the Cu(II) complex were found to be $0.5038 \times 104 \mathrm{~L} \mathrm{~mol}^{-1} \mathrm{~cm}^{-1}$ and $0.0039 \mu \mathrm{g} \mathrm{cm}^{-2}$, respectively. The structure of the prepared complex was investigated by using the continuous variation, mole ratio method and slope analysis method. The obtained results showed that the complex has (1:2) (M:L) molar ratio and these results showed that this method was more sensitive, more precise and accurate through the calculation of (Re, Erel, R.S.D)\%. The most important interferences were $\mathrm{Co}^{2+}, \mathrm{Cd}^{2+}, \mathrm{Zn}^{2+}, \mathrm{Ni}^{2+}, \mathrm{Mn}^{2+}, \mathrm{Pd}^{2+}, \mathrm{Fe}^{3+}$, thus suitable masking agents were used. This method was applied for the determination of $\mathrm{Cu}(\mathrm{II})$ in alloy. The obtained results were compared with flame atomic absorption spectrometry method and showed that results of both methods were in good agreement.
\end{abstract}

Keywords: azo-Schiff base compounds; 2-amino phenol Schiff base; precise and accuracy

\section{- INTRODUCTION}

Copper is a reddish-colored metal and a heavy metal that changes color and properties when it is combined with other elements forming different compounds [1-2]. Copper is a soft material that can be reacted chemically [3] or physically with external source [4]. In addition to that, its advantages include a slow rate of reaction with diluted acids [5-6]. Copper is a fundamental supplementary element to plants and other living species [7].

Copper has electrical conductivity, thermal conductivity, is oxidative and can undergo hydrolysis [8] and has the ability to be used in the manufacturing of alloys [9-10], including biscuit alloy with zinc. Copper compounds are also used in analytical chemistry, such as the Vlnk solution which is used in the detection of sugars [11]. Copper can enter the composition of the skin and hair, for example in the form of Batali that is responsible for coloring hair and skin. In addition, copper can enter the formation of joints and nerves, which is responsible for the sense of taste. Copper is also involved in the synthesis of many enzymes, thus maintaining the activity and health of the heart.

Many techniques can be used to determine copper percentage in its compounds. Some of these are atomic absorption spectrometry [12-14], inductive coupled plasma-emission spectrometry [15], potentiometry [16], derivative potentiometric stripping analysis [17], flow injection catalytic photometric method [18-19], and inductive coupled plasma-mass spectrometry [19]. Several studies were published for spectral estimation of $\mathrm{Cu}$ (II).

Rao [20] was able to estimate copper(II) spectrophotometrically by using an organic detector (4-

Esraa Raafid et al. 
HBTS), where the yellow colored complex that was formed showed a maximum absorption peak at $370 \mathrm{~nm}$, in $\mathrm{pH}=$ 6.5 , with absorption coefficient of $\left(2.85 \times 10^{4}\right) \mathrm{L} \mathrm{mol}^{-1} \mathrm{~cm}^{-1}$, sandal sensitivity of $0.00032 \mu \mathrm{g} \mathrm{cm}^{-1}$, and value of \% R.S.D equal to (0.025). A colorimetric method was used for the determination of $\mathrm{Cu}(\mathrm{II})$ by using chromogenic reagent (CDSAI) in a neutral medium at $588 \mathrm{~nm}$ with concentration range of 6-0.25 $\mu \mathrm{g} \mathrm{mL}^{-1}$ and D.L $=0.15 \mu \mathrm{g} \mathrm{mL}^{-1}$ [21].

The aim of this work is to prepare a new reagent to be used in a new method, that is more sensitive, easy and have low cost for the extraction and determination of copper(II) ion from industrial samples, and to study all the conditions that affects the determination process, such as the $\mathrm{pH}$ of reaction solution, the time needed to complete the reaction of the complex formation, and the optimum concentration of reagent that will result in complete complexation reaction with copper ions.

\section{- EXPERIMENTAL SECTION}

\section{Materials}

All solvents and chemical Reagents used in this study have high purity and are supplied by B.D.H, Fluka and Merck companies without any additional purification processes. The materials used were ethanol absolute, glacial acetic acid, $p$-aminoacetophenone, 2-naphthol, sodium nitrite, hydrochloric acid, sodium hydroxide, and $o$-aminophenol.

\section{Instrumentation}

All techniques that were used in the characteristic study of the new synthesized ligand and its complexes were a-UV-6100 PC Double beam Spectrophotometer (EMCLAB, Germany), FT-IR Spectrophotometer 8400S (Shimadzu, Japan), pH-meter (InoLab, WTW, 135i, Germany), Conductivity meter (Digital, InoLab, Germany), Melting point instrument (SMP 30, Stuart, England), Balance BL 2105 (Sartorius, Germany), Mova $400 \mathrm{MHZ},{ }^{1} \mathrm{H}-\mathrm{NMR}$, and ${ }^{13} \mathrm{C}-\mathrm{NMR}$ spectrophotometer.

\section{Procedure}

\section{Synthesis of the new ligand (HPDN)}

The ligand 1-((4-(1-(2-hydroxyphenylimino) ethyl) phenyl)diazenyl)naphthalene-2-ol (HPDN) was synthesized in two steps (Scheme 1). The first step was to prepare the azo derivative by reacting $p$ aminoacetophenone with 2-naphthol in controlled conditions and the addition of azo which was conducted

The first step:

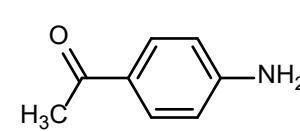

p-Aminoacetophenone

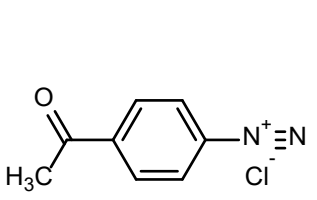

Diazonium salt
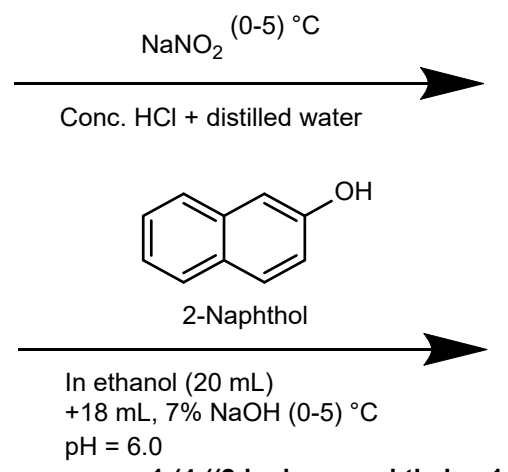

1-(4-((2-hydroxynaphthalen-1-yl)diazenyl)phenyl)ethanone (HNDP)

The second step:

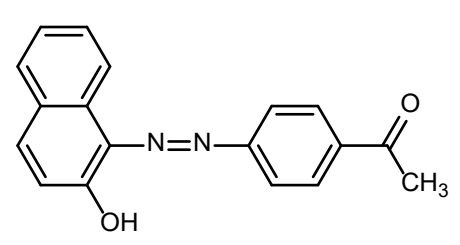

HNDP
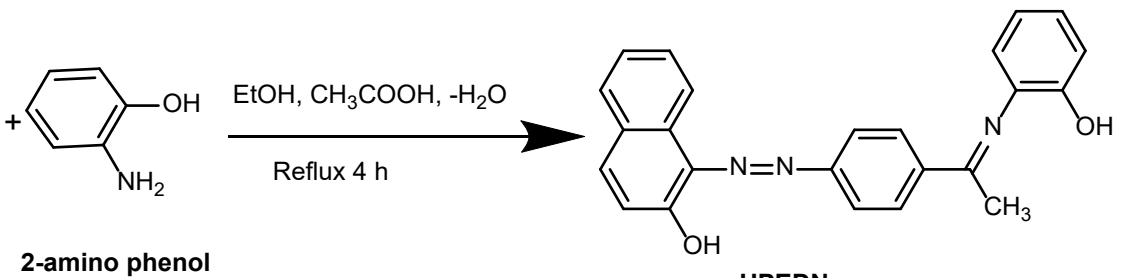

HPEDN

Scheme 1. Pathway of synthesis of 1-((4-(1-(2-hydroxyphenylimino)ethyl)phenyl)diazenyl)naphthalene-2-ol (HPEDN) ligand (step one and two) 
in a snowy environment due to the exothermic process of the reaction. The obtained precipitate showed a dark red color with a yield of $75.37 \%$ and melting point of $145-147^{\circ} \mathrm{C}$.

The second step includes the reaction of the Azo derivative 1-(4-((2-hydroxynaphthalen-1-yl)diazenyl) phenyl)ethanone (HNDP) with 2-aminophenol, by refluxing of the mixture for $4 \mathrm{~h}$ which was later cooled to room temperature, dried and recrystallized with absolute ethyl alcohol. The resultant precipitate yield was $72.51 \%$ of reddish brown crystals and the melting point was $178-180^{\circ} \mathrm{C}$.

\section{Preparation of buffer solution}

The buffer solution was prepared by dissolving $0.7708 \mathrm{~g}, 0.01$ mole of ammonium acetate in $1000 \mathrm{~mL}$ of distilled water. Different $\mathrm{pH}$ values were obtained by adding certain amounts of concentrated ammonia solution or concentrated acetic acid in order to prepare solutions with $\mathrm{pH}$ range between 4 and 12 .

\section{Synthesis of the divalent copper(II) complex}

The metal complexes were prepared by the molar ratio (1:2) (M:L) by dissolving $(1 \mathrm{mmol})$ of the metal chloride salt in $10 \mathrm{~mL}$ of buffer solution in optimal acidic function. Chlorides were selected as good leaving groups and to prevent interference with negative ions and for ease of use in the buffer solution with optimum acid function and $2 \mathrm{mmol}$ of ligand was dissolved in $20 \mathrm{~mL}$ of ethanol absolute. The metal ligand mixture solution was then heated at $\left(50-60{ }^{\circ} \mathrm{C}\right)$ for $1 \mathrm{~h}$, and the precipitate was washed and recrystallized with ethanol absolute and later dried in air. Table 1 shows the physical properties of the ligand and its complexes.

\section{- RESULTS AND DISCUSSION}

\section{UV-Visible Spectrophotometry}

The absorption spectra of the (HPEDN) ligand solution in ethanol was recorded at wavelengths from 200-800 $\mathrm{nm}$. The maximum absorption peak of the ligand was at $326 \mathrm{~nm}$. The maximum absorption of the $\mathrm{Cu}^{2+}$ complex was at $500 \mathrm{~nm}$ after the application of optimal conditions. This observation confirms the formation of stable complexes as shown in Fig. 1 and Table 2.

When comparing absorption spectra of the ligand with that of the complex, a clear difference can be observed in the value of the maximum absorption peak which indicates a red shift and the formation of a complex with higher absorption in comparison with the ligand [22].

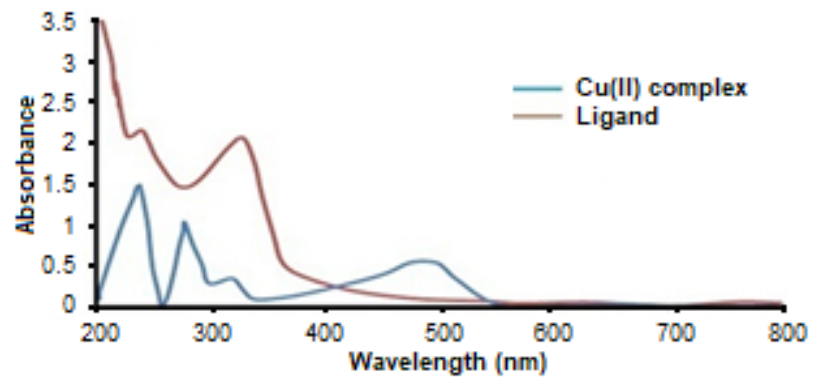

Fig 1. Electronic spectra for HPEDN ligand and its $\mathrm{Cu}(\mathrm{II})$ complex

Table 1. Physical properties of the azo-Schiff base ligand and its complexes

\begin{tabular}{|c|c|c|c|c|c|c|c|c|}
\hline \multirow{2}{*}{ No. } & \multirow{2}{*}{ Molecular formula } & \multirow{2}{*}{ Color } & \multirow{2}{*}{$\begin{array}{l}\text { m.p } \\
\left({ }^{\circ} \mathrm{C}\right)\end{array}$} & \multirow{2}{*}{$\begin{array}{c}\text { Yield } \\
(\%)\end{array}$} & \multicolumn{3}{|c|}{$\mathrm{Am} / \mathrm{Ohm}^{-1} \mathrm{~mol}^{-1} \mathrm{~cm}^{2}$} & \multirow{2}{*}{$\begin{array}{l}\text { Reaction } \\
\text { time }\end{array}$} \\
\hline & & & & & DMF & Ethanol & DMSO & \\
\hline 1 & $\mathrm{C}_{24} \mathrm{H}_{19} \mathrm{~N}_{3} \mathrm{O}_{2}$ & Reddish brown & $178-180$ & 72.51 & - & - & - & $4 \mathrm{~h}$ \\
\hline 2 & {$\left[\mathrm{Cu}\left(\mathrm{C}_{24} \mathrm{H}_{19} \mathrm{~N}_{3} \mathrm{O}_{2}\right)_{2} \mathrm{Cl}_{2}\right]$} & Brown & $196-198$ & 63.11 & 16.5 & 11.3 & 10.3 & $1 \mathrm{~h}$ \\
\hline
\end{tabular}

Table 2. The electronic transitions for HPEDN ligand and complex

\begin{tabular}{llcc}
\hline Molecular formula of ligand & $\lambda(\mathrm{nm})$ & Wave number $\left(\mathrm{cm}^{-1}\right)$ & Transition type \\
\hline $\mathrm{C}_{24} \mathrm{H}_{19} \mathrm{~N}_{3} \mathrm{O}_{2}$ & 326 & 30674 & $\mathrm{n} \rightarrow \pi^{\star}$ \\
& 237 & 42194 & $\pi \rightarrow \pi^{*}$ \\
\hline$\left[\mathrm{Cu}\left(\mathrm{C}_{24} \mathrm{H}_{19} \mathrm{~N}_{3} \mathrm{O}_{2}\right)_{2} \mathrm{Cl}_{2}\right]$ & 500 & 20000 & $\mathrm{CT}$ \\
& 314 & 31840 & $\mathrm{n} \rightarrow \pi^{\star}$ \\
& 285 & 35087 & $\pi \rightarrow \pi^{*}$ \\
& 226 & 44247 & $\pi \rightarrow \pi^{*}$ \\
\hline
\end{tabular}

Esraa Raafid et al. 


\section{Study of the Optimal Conditions for the Formation of the Complex}

\section{Effect of $\mathrm{pH}$ solution on the formation of the complex}

A series of copper ions solutions with ligand (HPEDN) were prepared at $\mathrm{pH}$ ranges of $4-12$, and were each measured for their absorbance at the maximum wavelength of the copper complex. The results showed that the best $\mathrm{pH}$ was 9 , which gave the highest absorbance for the metal complex. It was also observed that the absorption values were varied with variation of $\mathrm{pH}$ values of the solution. This may be due to the change in chemical nature of the ligand or the competition between hydroxyl ions in the ligand with metal ions. It was also found that absorption values of the complex decreased with increasing value of $\mathrm{pH}$, and this can be attributed to the deposition of ions of the element and the formation of an unstable complex [23], as shown in Fig. 2.

\section{Effect of the concentration of ligand on the complex formation}

To investigate the effect of the concentration of ligand on the complex formation, a series of solutions containing different concentrations of ligand (HPEDN) ranging from $0.5 \times 10^{-4}-4 \times 10^{-4} \mathrm{M}$ were mixed with constant concentration $\left(1 \times 10^{-4} \mathrm{M}\right)$ of copper(II) ion solution. The $\mathrm{pH}$ of solution was adjusted to 9 , and then the absorbance was measured against water and ethanol as a blank solution. The obtained results showed that the optimal concentration of ligand was $1.5 \times 10^{-4} \mathrm{M}$, which gave the highest absorption of the complex. Higher

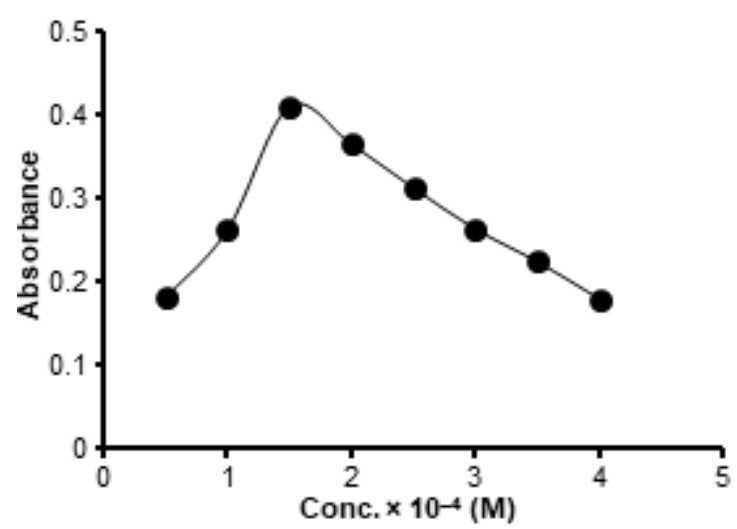

Fig 3. Effect of ligand concentration concentrations of ligand, caused a decrease in absorption intensity this may be due to the formation of new species in the solution that are absorbed at different wavelengths and possibility to the condensation of the ions or the solubility of the reagent with the solvent completely. As shown in Fig. 3.

\section{Effect of time on the formation of the Cu(II) complex}

Fig. 4 shows that the formed complex gave high absorbance after 15 min of reaction time and remained constant for $48 \mathrm{~h}$ at optimal conditions. The results of this study showed that the prepared ligand can be used to estimate the concentration of copper by forming a stable complex, similar to other reagents that have been used to estimate the concentration of other ions spectrally [24].

The effect of additive sequencing of ligand, metal ion and buffer solution on the absorption intensity of the

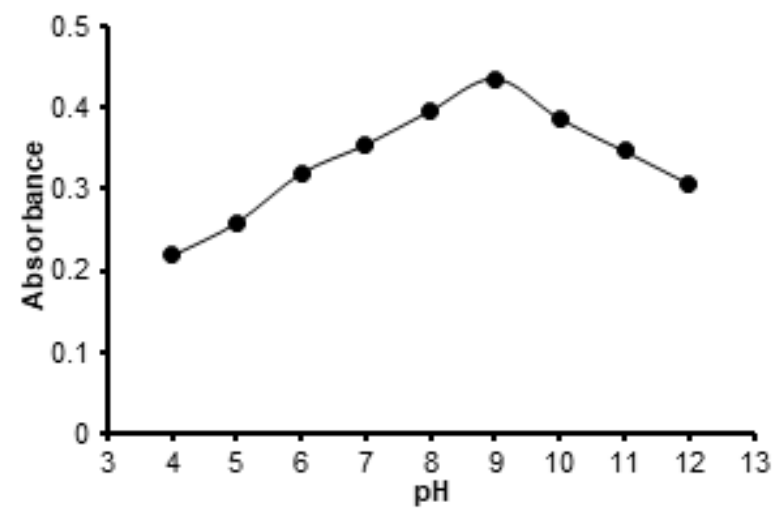

Fig 2. Effect of $\mathrm{pH}$ values of solution on complex formation

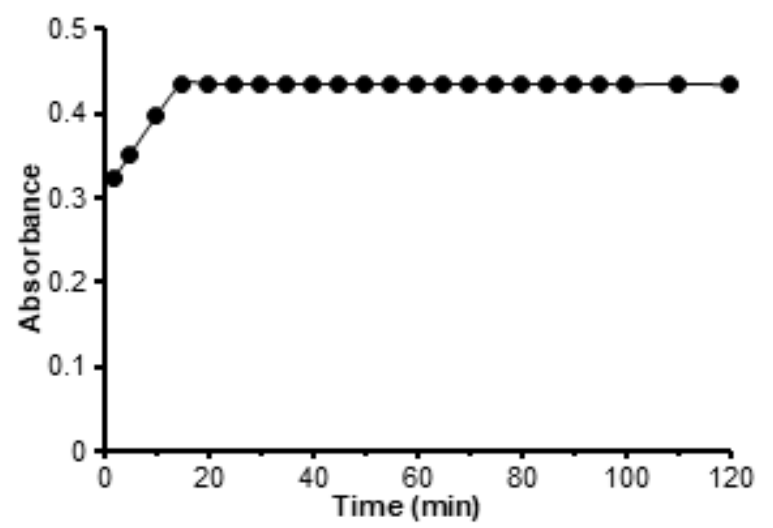

Fig 4. Effect of time on the stability of the copper(II) complex 
formed complex was investigated in this part. The obtained results showed first and second sequential succession which exhibited low absorption values. This is due to positive and negative completion of ions of the acid and base in the metal bonding, that leads to low absorption values. Therefore, the third sequencing was used to determine the absorption values and to prepare the complex as shown in Table 3.

\section{Effect of temperature}

The effect of temperature on the stability of the synthesized complex was investigated in temperatures ranging between 5 and $50{ }^{\circ} \mathrm{C}$. The obtained results showed that the copper complex absorbance remained almost constant at $15-30^{\circ} \mathrm{C}$. After that, the absorption decreased. This result may be due to the decomposing of the complex at temperatures above $30{ }^{\circ} \mathrm{C}$, so it is preferable to study copper complex within this range of temperature. The results are shown in Fig. 5.

\section{Mole Ratio Method}

The possible compositions for the preparation of the complex were determined using the molar ratio method. The method was conducted by taking different volumes of ligand and a constant volume of the metal ion at the same concentration. The results showed that the complex

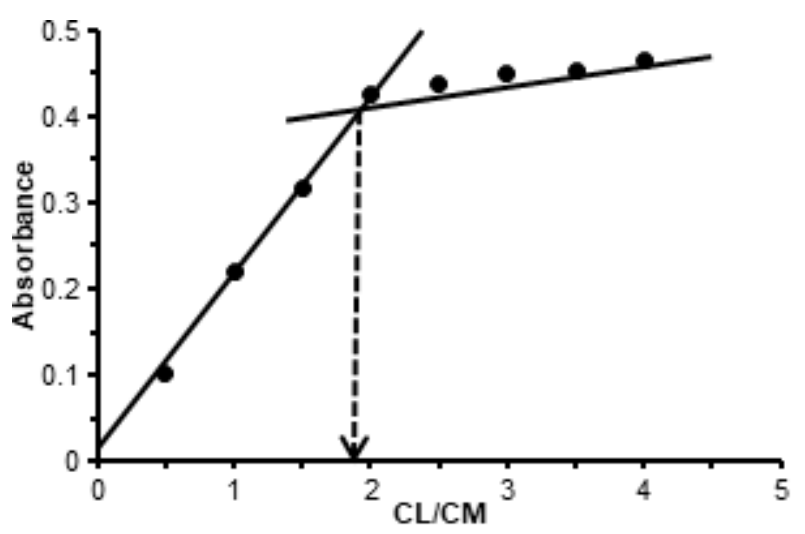

Fig 6. Molar ratio method of copper(II) complex has the mole ratio of (1:2) (Metal:Ligand) as shown in Fig. 6.

\section{The Continuous Variation Method (Job Method)}

In this method, different volumes of both the ligand and the metal were selected with the same concentration at the optimal acid function and the absorbance of each solution was measured at the maximum wavelength of the copper complex. When drawing the absorbance values against $\frac{\mathrm{Vm}}{\mathrm{Vm}+\mathrm{Vl}}, \mathrm{Vm}$ represents the volume of metal and $\mathrm{Vl}$ is the volume of ligand. The ratio was found to be (1:2), one mole of metal to 2 moles of the ligand as shown in Fig. 7.

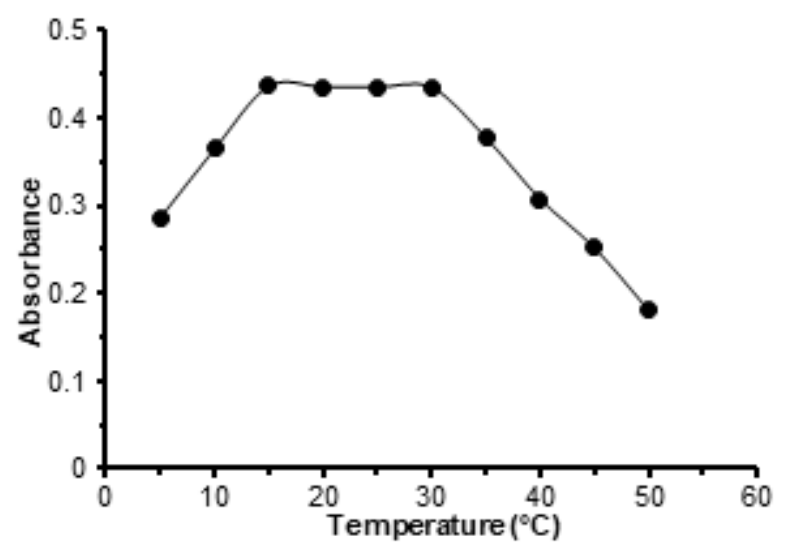

Fig 5. Effect of temperature on the stability of the complex

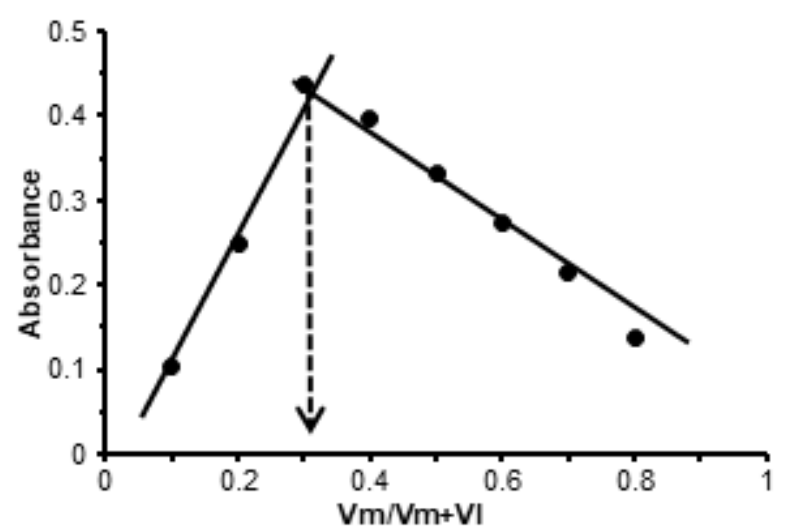

Fig 7. Continuous variation method of copper(II) complex

Table 3. Effect of Sequence of addition on the formation of $\mathrm{Cu}^{2+}$ complex with HPEDN ligand at $\mathrm{pH}=9$

\begin{tabular}{clc}
\hline $\begin{array}{c}\text { The sequence } \\
\text { of addition number }\end{array}$ & \multicolumn{1}{c}{ Sequence of addition } & Absorbance \\
\hline 1 & Metal + buffer solution to adjusting pH + ligand & 0.3166 \\
2 & Ligand + Metal + buffer solution to adjusting pH & 0.3325 \\
3 & Metal + Ligand + buffer solution to adjusting pH & 0.4357 \\
\hline
\end{tabular}

Esraa Raafid et al. 
The values of the stability constant of the complex were calculated according to the following equations and the value of stability and instability constants are shown in Table 4.

$\mathrm{MLn} \rightarrow \mathrm{M}^{2+}+\mathrm{nL}$

$(1-\alpha) \mathrm{c} \quad \alpha \mathrm{c} \quad \mathrm{n} \alpha \mathrm{c}$

$\mathrm{K}_{\text {inst }}=\frac{(\mathrm{ac})(\mathrm{nac})^{\mathrm{n}}}{\mathrm{c}(1-\mathrm{a})}$

$\mathrm{K}_{\mathrm{st}}=\frac{1}{\mathrm{~K}_{\text {inst }}}$

The results of the stability constants showed that the copper complex is more stable. The reason is that the higher the atomic number, the higher the nuclear charge, causing it to have more ability to attract ligands compared to other ions in the same period of the periodic table, which leads to more electric field absorbed by the positive ions of the ligand, which increases the stability of the complex [26].

\section{Effect of Interference and Masking Reagent on the Absorption of the Copper(II) Complex}

The effect of interference on the absorption of the copper complex with ligand was studied by selecting several positive and negative ions as shown in Table 5.

Table 4. Absorption values $\left(\mathrm{A}_{\mathrm{s}}\right)$ and $\left(\mathrm{A}_{\mathrm{m}}\right)$ as well as values of each $(\alpha)$ and $\left(\mathrm{K}_{\mathrm{st}}\right)$ and $\left(\mathrm{K}_{\text {inst }}\right)$ of the copper complexes

\begin{tabular}{lcccccc}
\hline Metal complex & $\mathrm{A}_{\mathrm{s}}$ & $\mathrm{A}_{\mathrm{m}}$ & $\alpha$ & $\mathrm{K}_{\text {inst }}$ & $\mathrm{K}_{\mathrm{st}}$ & $\log \mathrm{K}_{\mathrm{st}}$ \\
\hline $\mathrm{CuL}$ & 0.3922 & 0.4536 & 0.1353 & $1.145 \times 10^{-10}$ & $8.728 \times 10^{9}$ & 9.956 \\
\hline
\end{tabular}

Table 5. Effect of addition of positive and negative ions on the absorption values of the divalent copper complex

\begin{tabular}{|c|c|c|c|c|}
\hline Foreign ions & $\frac{1 \times 10^{-4} \mathrm{M}}{\text { Absorbance after addition of ions }}$ & $\mathrm{d}$ & $\mathrm{E} \%$ & $\% \operatorname{Re}$ \\
\hline \multicolumn{5}{|l|}{ Cation } \\
\hline Without Cation & 0.4374 & 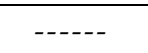 & $\begin{array}{l}---- \\
\end{array}$ & $\begin{array}{l}---- \\
-1\end{array}$ \\
\hline $\mathrm{Ni}^{+2}$ & 0.4266 & -0.012 & -2.46 & 97.54 \\
\hline $\mathrm{Co}^{+2}$ & 0.4305 & 0.00069 & -1.57 & 98.43 \\
\hline $\mathrm{Cd}^{+2}$ & 0.3992 & 0.0382 & -8.73 & 91.26 \\
\hline $\mathrm{Pd}^{+2}$ & 0.4564 & 0.019 & 4.34 & 104.34 \\
\hline $\mathrm{Mn}^{+2}$ & 0.4428 & 0.0054 & 1.23 & 101.34 \\
\hline $\mathrm{Fe}^{+2}$ & 0.3197 & -0.1207 & -27.5 & 72.41 \\
\hline $\mathrm{Zn}^{+2}$ & 0.2872 & -0.1512 & -34.3 & 65.66 \\
\hline \multicolumn{5}{|l|}{ Anion } \\
\hline Without anion & 0.4374 & ----- & ----- & ----- \\
\hline $\mathrm{CO}_{3}^{-2}$ & 0.3958 & -0.041 & -9.51 & 90.48 \\
\hline $\mathrm{SO}_{4}^{-2}$ & 0.4283 & -0.009 & -2.08 & 97.91 \\
\hline $\mathrm{C}_{2} \mathrm{O}_{4}^{-2}$ & 0.4207 & -0.016 & -3.81 & 96.18 \\
\hline $\mathrm{CH}_{3} \mathrm{COO}^{-2}$ & 0.3984 & -0.039 & -8.91 & 91.08 \\
\hline $\mathrm{NO}_{2}^{-1}$ & 0.4092 & -0.028 & -5.95 & 94.04 \\
\hline $\mathrm{SCN}^{-1}$ & 0.4163 & -0.021 & -0.99 & 99.00 \\
\hline $\mathrm{Cl}^{-1}$ & 0.3995 & -0.072 & -3.49 & 96.50 \\
\hline \multicolumn{5}{|l|}{ Masking agent } \\
\hline Without masking agent & 0.4374 & ----- & ----- & ----- \\
\hline Ascorbic acid & 0.2793 & -0.158 & -36.14 & 63.85 \\
\hline Potassium Thiocyanate & 0.4368 & -0.0006 & -0.137 & 99.862 \\
\hline EDTA & 0.1806 & -0.2568 & -58.71 & 41.28 \\
\hline Thiourea & 0.3512 & -0.0862 & -24.81 & 75.187 \\
\hline Potassium chloride & 0.4084 & -0.029 & -6.63 & 93.36 \\
\hline Tartaric acid & 0.2347 & -0.2027 & -46.34 & 53.65 \\
\hline Salicylic acid & 0.3095 & -0.1279 & -29.24 & 70.75 \\
\hline
\end{tabular}


The positive ions were found to decrease or increase the absorbance. This is due to the competition of these ions with the copper ion on the bonding with the reagent to form the complex, where part of the reagent is taken to be a new complex. The low absorbance values after the addition of the negative ions were due to their use as a masking reagent, where $\mathrm{KSCN}$ was used as a masking reagent to eliminate the effect of the interference by returning the absorption values to the original calculated output without interference [29].

\section{FTIR Spectra of the Ligand and the Complex}

Fig. 8 shows the IR FTIR spectra of the ligand and its complex, in which the ligand appeared as a narrow, weakintensity band at $3416 \mathrm{~cm}^{-1}$ due to the stretching vibrations of the hydroxide group in the ligand. When compared with the complex at $3454 \mathrm{~cm}^{-1}$, there was a change in the intensity, and location of the peak due to the bonding of the carboxyl group, after they lost their proton [30].

The ligand spectrum showed a medium-intensity absorption at $1666 \mathrm{~cm}^{-1}$ attributed to $v(\mathrm{C}=\mathrm{N})$ and this site suffered less displacement when aligned with copper as well as a change in intensity and shape in the complex spectra.

The ligand spectra have shown to have a strong absorption at $1413 \mathrm{~cm}^{-1}$, which is attributed to the vibration band of $v(\mathrm{~N}=\mathrm{N})$, that had undergone a shift toward a lower wavelength when it was associated with the metal. The consistency of copper and the ligand was observed by the nitrogen atom of the azo group.

The low frequency region is limited to $593 \mathrm{~cm}^{-1}$ absorption bands for the metal-oxygen bonds and $473 \mathrm{~cm}^{-1}$ due to metal-nitrogen bonds. This result is due to the formation of a homogeneous bond between the deposited atoms with the central copper ion [31]. All these bands are summarized in Table 6 .

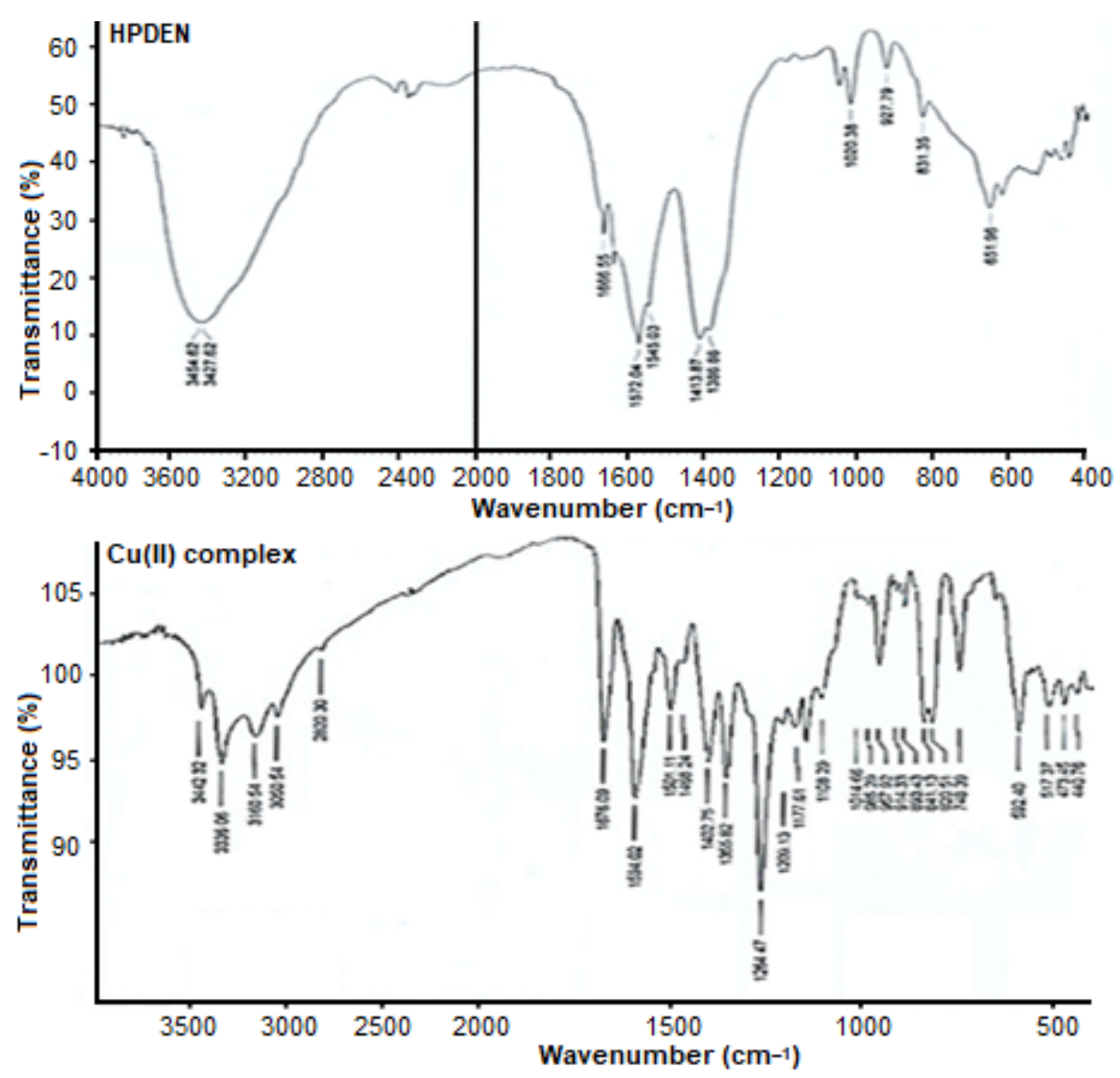

Fig 8. FT-IR spectrum of the ligand (HPDEN) and its complex with $\mathrm{Cu}$ (II) 
Table 6. Typical FT-IR absorption frequencies for reagent and complexes

\begin{tabular}{llllll}
\hline Compound & OHv & N=Cv & N=Nv & M-Nv & M-Ov \\
\hline Ligand HPEDN & $3454(\mathrm{~s})$. & $1666(\mathrm{~m})$. & $1413(\mathrm{~s})$. & - & - \\
$\mathrm{Cu}(\mathrm{II})$ complex & $3442(\mathrm{w})$. & $1676(\mathrm{w})$. & $1468(\mathrm{w})$. & 473(w.) & 593(w.) \\
\hline w.: weak s.: strong m.: medium comp.: complex
\end{tabular}

\section{${ }^{1} \mathrm{H}-\mathrm{NMR}$ and ${ }^{13} \mathrm{C}-\mathrm{NMR}$ Spectra of Ligand (HPEDN)}

The ${ }^{1} \mathrm{H}-\mathrm{NMR}$ Spectra of the ligand shows the chemical displacements of aromatic and elliptical protons. The single band at $9.8491 \mathrm{ppm}$ belong to the proton of the hydroxyl group $(\mathrm{OH})$, the three single bands at 2.5895 , 2.6189 and $2.6471 \mathrm{ppm}$ are attributed to the protons of the methyl group $\left(\mathrm{CH}_{3}\right)$, the multiple bands at 6.7574 to $8.4526 \mathrm{ppm}$ belong to the nine protons of the aromatic rings, while the band at $(2.500 \mathrm{ppm})$ relates to $\left(\mathrm{DMSO} \mathrm{d}^{6}\right)$ [32]. Proton NMR spectra of the ligand are shown in Fig. 9. ${ }^{13} \mathrm{C}$-NMR spectra of the ligand, shows the appearance of a single band at $39.520 \mathrm{ppm}$ which belongs to the carbon of the methyl group $\left(\mathrm{CH}_{3}\right)$, the single band at $155.3790 \mathrm{ppm}$ belongs to the carbon of azomethine $(-\mathrm{C}=\mathrm{N}-)$, and the multiple bands at 108.6402 to $145.3493 \mathrm{ppm}$ belong to the 22 carbons of the aromatic rings [32].

\section{The Suggested Structures of the Copper(II) Complex}

From the results of the electrical conductivity, molar ratios and continuous variation methods and also all the spectral methods applied for the study of the copper(II) complex [33-34], we concluded that the complex structure consists of 2 moles of ligand and one mole of metal and the complex was uncharged, therefore the shape of the complex must be octahedral with the hybridization of $\mathrm{d}^{2} \mathrm{sp}^{3}$ as shown in Fig. 10.

\section{Construction of the Calibration Curve}

In order to construct a calibration curve, a series of different concentrations of the metal ion were prepared ranging from 1.7-8.4 $\mu \mathrm{g} \mathrm{mL}^{-1}$ with constant concentration of the ligand $\left(1.5 \times 10^{-4} \mathrm{M}\right)$ using absolute ethanol as the

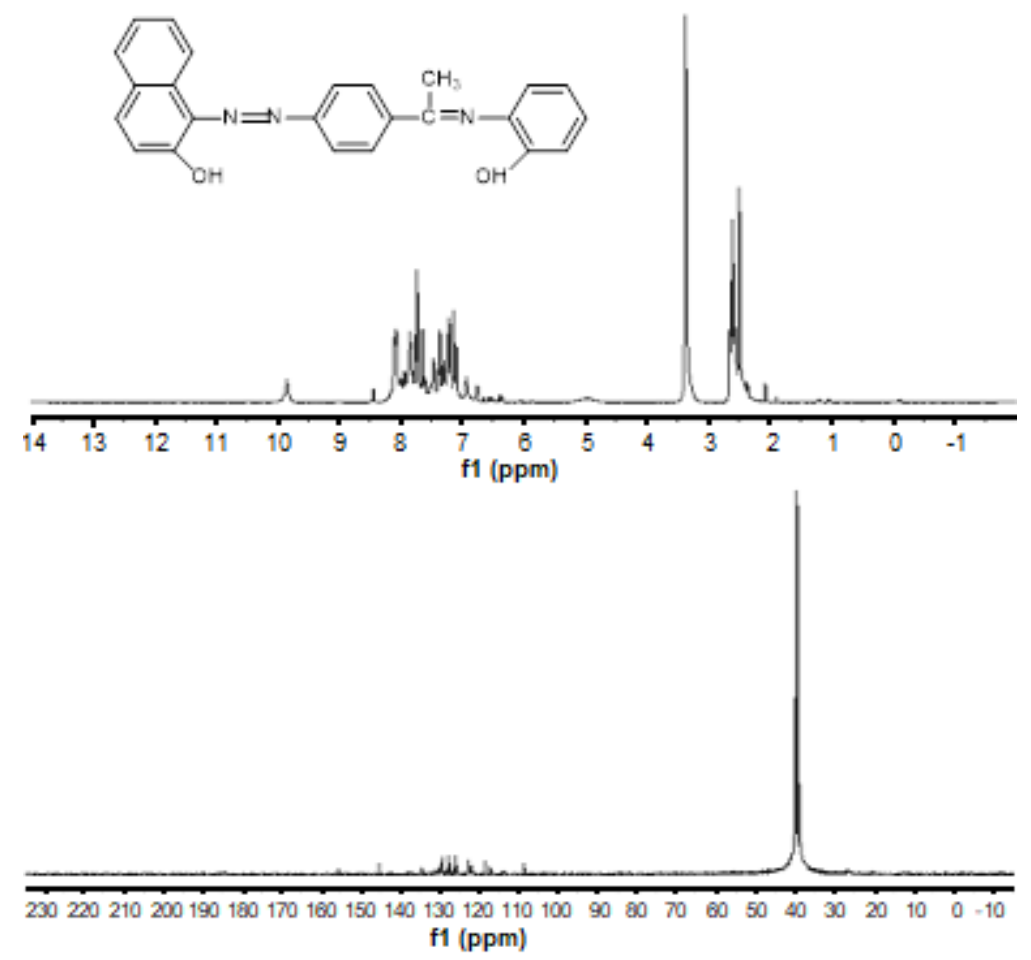

Fig 9. ${ }^{1} \mathrm{H}-\mathrm{NMR}$ and ${ }^{13} \mathrm{C}$-NMR spectra of ligand (HPEDN) 


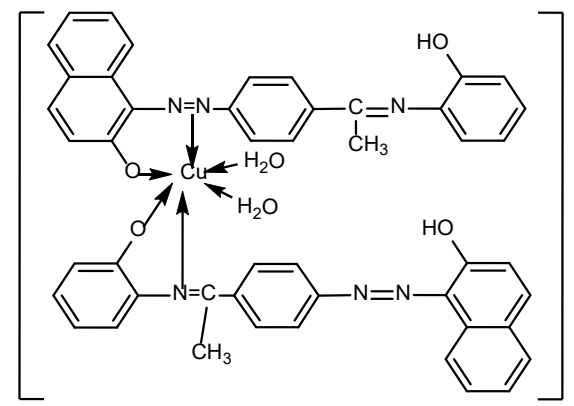

Fig 10. The suggested structures of copper(II) complex

solvent, where the results showed that the calibration curve follows the Lambert Beer's law for a range of concentrations 1.7-5.4 $\mu \mathrm{g} \mathrm{mL}^{-1}$. The Sandell's Sensitivity was equal to 0.0039 , while the limit of detection (LOD) and limit of quantification (LOQ) was equal to 0.2217 and 0.7385 , respectively. This shows that the method is highly sensitive and can be used to determine metals with low concentrations with agreeable accuracy and precision under the optimal conditions of the reaction [25]. These results were calculated by Eq. 3,4 and 5 as shown in Table 7 and Fig. 11.

$\mathrm{LOD}=\frac{3 \mathrm{SD}}{\mathrm{Slop}}$

$\mathrm{LOQ}=\frac{10 \mathrm{SD}}{\text { Slop }}$

$\mathrm{SD}=\sqrt{\frac{\sum(\mathrm{Xi}-\overline{\mathrm{X}})^{2}}{\mathrm{n}-1}}$

where $x i$ is the absorbance, $\bar{x}$ is the mean of the absorbance, and $\mathrm{n}$ is the number of the measurement.

\section{Precision}

The precision of the analytical method was determined by calculating the amount of standard deviation (SD) for five measurements of absorbance, and the relative standard deviation (\% RSD) by dividing the $\mathrm{SD}$ with the mean of the absorbance $(\overline{\mathrm{x}})$ of the complex in optimal conditions as shown in Table 8. The sensitivity of this method was calculated using the detection limit (DL) and the limit of appreciation. This method is therefore used to estimate metal ions [27]. These values were calculated by using Eq. 3, 4, 5 and 6 . The result showed that this method is able to be used to determine $\mathrm{Cu}$ (II) concentrations with high precision compared with other spectrophotometric methods.

$\mathrm{RSD} \%=\mathrm{SD} / \overline{\mathrm{x}}$

\section{Accuracy}

Accuracy means the closeness of the practical value from the theoretical value to determine if the results of an analytical method are accurate. The accuracy of the analytical method in this research was calculated by using the percentage relative error and the preprocessing ratio of the previously prepared complexes as shown in Table 9. The results show that the method that

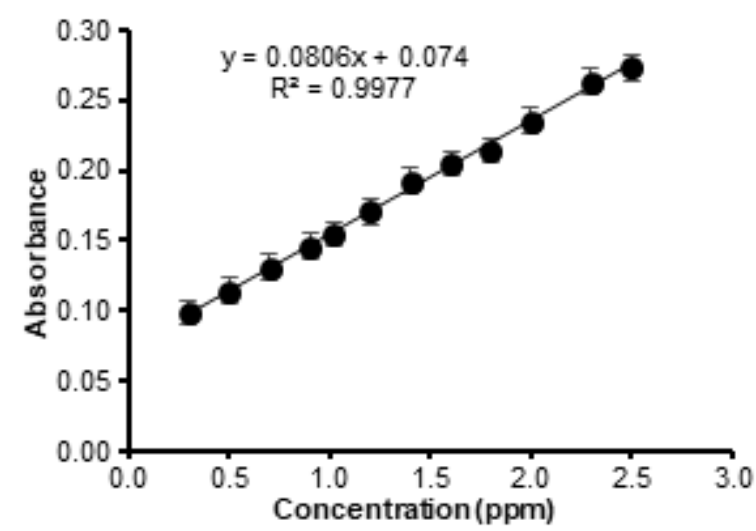

Fig 11. Calibration curve of the copper complex

Table 7. Construction of calibration curve of metal complexes

\begin{tabular}{ll}
\hline$\lambda$ max $(\mathrm{nm})$ & 500 \\
Beer's Law limit $\left(\mu \mathrm{g} \mathrm{mL}^{-1}\right)$ & $1.7-5.4$ \\
Molar Absorptivity $\left(\mathrm{L} \mathrm{mol}^{-1} \mathrm{~cm}^{-1}\right)$ & $0.5038 \times 10^{4}$ \\
Sandell's Sensitivity $\left(\mu \mathrm{g} \mathrm{cm}^{-2}\right)$ & 0.0039 \\
Limit of Detection $\left(\mu \mathrm{g} \mathrm{m}^{-1}\right)$ & 0.2217 \\
Limit of Quantification $\left(\mu \mathrm{g} \mathrm{mL} \mathrm{mL}^{-1}\right)$ & 0.7385 \\
Regression Equation & $\mathrm{y}=0.2519 \mathrm{x}+0.0043$ \\
Slope & 0.2520 \\
Correlation coefficient $(\mathrm{R})$ & 0.9994 \\
\hline
\end{tabular}

Table 8. Values of standard deviation, percentage standard deviation

\begin{tabular}{lccccccccc}
\hline No. & 1 & 2 & 3 & 4 & 5 & Average $\overline{\mathrm{x}}$ & Sum $(\mathrm{xi}-\overline{\mathrm{x}})^{2}$ & SD & \% RSD \\
\hline Complex of $\mathrm{Cu}(\mathrm{II})$ & 0.4378 & 0.4377 & 0.4377 & 0.4376 & 0.4376 & 0.4377 & $3 \times 10^{-7}$ & 0.00086 & 0.1964 \\
\hline
\end{tabular}


Table 9. The relative percentage error and the pre-processing ratio of the complex

\begin{tabular}{lcccc}
\hline Complex ion & Analytical value $\left(\mathrm{mol} \mathrm{L}^{-1}\right)$ & $\mathrm{d}$ & $\% \mathrm{E}_{\text {real }}$ & $\% \mathrm{Re}$ \\
\hline $\mathrm{Cu}(\mathrm{II})$ & $0.971 \times 10^{-4}$ & $-0.029 \times 10^{-4}$ & -2.9 & 97.1 \\
\hline
\end{tabular}

Table 10. The percentages of copper determination by ligand in a copper alloy using an atomic absorption method

\begin{tabular}{lccccccc}
\hline Sample & $\begin{array}{c}\text { Content } \\
\%\end{array}$ & $\begin{array}{c}\text { By Spectrophotometric } \\
\text { method \% }\end{array}$ & $\% \mathrm{E}_{\mathrm{rel}}$ & $\% \mathrm{Re}$ & $\begin{array}{c}\text { By Flame atomic } \\
\text { absorption } \%\end{array}$ & $\% \mathrm{E}_{\mathrm{rel}}$ & $\% \mathrm{Re}$ \\
\hline Alloy copper & 70 & 69.4 & 0.6 & 100.6 & 68.8 & 1.2 & 101.2 \\
\hline
\end{tabular}

was used to measure the metal concentration using ligand (HPDN) was highly accurate [28].

$\% \mathrm{E}_{\text {real }}=\frac{\mathrm{d}}{\mu} \times 100$

where $\mu=$ analytical value, $d=$ analytical value - theoretical value

\section{Applications}

The prepared ligand was used as a reagent to determine copper in an alloy that contains $70 \%$ copper and $30 \%$ zinc, using the UV-Vis method, and the results were compared to the flame atomic absorption method as shown in Table 10.

From Table 10 we can observe the compatibility between the UV-Vis method and the atomic absorption method, so we can conclude that the UV-Vis method can be widely used in the determination of copper in different models with precision, selectivity and high sensitivity.

\section{- CONCLUSION}

The current study showed the success of the preparation of a reagent and the possibility of its use in determining micro amounts of copper in different models with high accuracy and sensitivity by forming a color complex. The optimal conditions to obtain the copper(II) complex were: $\mathrm{pH}=9$, temperature $=0-50{ }^{\circ} \mathrm{C}$, the ratio of ligand to metal(1:2), SD $=0.00086, \% \operatorname{RSD}=0.1964$, $\mathrm{DL}\left(\mu \mathrm{g} \mathrm{mL} \mathrm{m}^{-1}\right)=0.2217$. According to this study, we can suggest that the shape of the complex must be an octahedral shape with the hybridization of $\mathrm{d} 2 \mathrm{sp} 3$.

\section{- ACKNOWLEDGMENTS}

The authors would like to thank Department of Chemistry, College of Education for Pure Science, University of Kerbala and College of Science, Babylon University in Iraq for funding this work.

\section{- REFERENCES}

[1] Wells, A.F, 1945, Structural Inorganic Chemistry, $4^{\text {th }}$ Ed., Clarendon Press-Oxford, London, 439, 811, 954-973.

[2] Greenwood, N., and Earnshow A., 1997, Chemistry of the Elements, $2^{\text {nd }}$ Ed., Elsevier, Oxford, 1174.

[3] Fouad, H.K., Atrees, M.S., and Badawy, W.I., 2016, Development of spectrophotometric determination of beryllium in beryl minerals using chrome Azurol S, Arabian J. Chem., 9 (Suppl. 1), S235-S239.

[4] Supong, K, and Usapein, P., 2019, Reliable determination of copper complex ions in synthetic wastewater using flame atomic absorption spectrophotometry, Water Sci. Technol., 79 (5), 833-841.

[5] Mohammed, S.F., and Musa, F.H., 2014, Synthesis and characterization of $\mathrm{Co}(\mathrm{II}), \mathrm{Ni}(\mathrm{II}), \mathrm{Cu}(\mathrm{II})$, $\mathrm{Cd}(\mathrm{II})$ and $\mathrm{Hg}$ (II) complexes with a new derivative of L-ascorbic acid, J. Kerbala Univ., 7 (4), 42-50.

[6] Li, M., and Zinkle, S.J., 2012, "Physical and mechanical properties of copper and copper alloys in Comprehensive Nuclear Materials, Vol. 4, Elsevier, Amsterdam, 667-690.

[7] Shiyab, S., 2018, Phytoaccumulation of copper from irrigation water and its effect on the internal structure of lettuce, Agriculture, 8(2), 29.

[8] Li, M., and Zinkle, S.J., 2012, "Physical and mechanical properties of copper and copper alloys" in Comprehensive Nuclear Materials, Vol. 4, Eds. Konings, R.J.M., Elsevier, Oxford, 667-690.

[9] Saranya, R., Rajasekaran, J., and Selvaraj, S.J., 2017, Synthesis and characterization of biologically important $\mathrm{Zn}$ (II), $\mathrm{Cu}(\mathrm{II})$ and $\mathrm{Co}(\mathrm{II})$ metal complexes in the 3D- series, J. Chem. Pharm. Sci., 1, 64-73. 
[10] Ahuja, B., Karg, M., Nagulin, K.Y., and Schmidt, M., 2014, Fabrication and characterization of high strength $\mathrm{Al}-\mathrm{Cu}$ alloys processed using laser beam melting in metal powder bed, Physics Procedia, 56, 135-146.

[11] Chaudhary, N.K., and Mishra, P., 2017, Metal complexes of a novel Schiff bases on penicillin: Characterization, molecular modeling, and antibacterial activity study, Bioinorg. Chem. Appl., 2017, 6927675.

[12] Khdeeja, J.A., Layla, A.M., Fatima, J.A., and Haider, N.R., 2015, New spectrophotometric determination of copper(II) using an organic reagent derived from imidazole and 4-aminoantypyrine and applied onto different samples, J. Chem. Pharm. Sci., 8 (2), 201207.

[13] Seidi, S., and Alavi, L. 2019, Novel and rapid deep eutectic solvent (DES) homogeneous liquid-liquid micro-extraction (HLLME) with flame atomic absorption spectrometry (FAAS) detection for the determination of copper in vegetables, Anal. Lett., 52 (13), 2092-2106.

[14] Yang, Q., Tang, G.P., Tian, L.F., Wei, Q.L., and Wang, C., 2015, Determination of trace copper in vanadium alloy by flame atomic absorption spectrometry, Adv. Mater. Res., 1120-1121, 13951398.

[15] Karadjov, M., Velitchkova, N., Veleva, O., Velichkov, S., Markov, P., and Daskalova, N., 2016, Spectral interferences in the determination of rhenium in molybdenum and copper concentrates by inductively coupled plasma optical emission spectrometry (ICP-OES), Spectrochim. Acta, Part B, 119, 76-82.

[16] Pięk, M., Fendrych, K., Smajdor, J., Piech, R., and Paczosa-Bator, B., 2017, High selective potentiometric sensor for determination of nanomolar con-centration of $\mathrm{Cu}$ (II) using a polymeric electrode modified by graphene/7,8,8tetracyanoquinodimethane nanoparticles, Talanta, $170,41-48$.

[17] Scarano, G., Morelli, E., Seritti, A., and Zirino, A., 1990, Determination of copper in seawater by anodic stripping voltammetry using ethylenediamine, Anal. Chem., 62 (9), 943-948.

[18] Ohno, S., Tanaka, M., Teshima, N., and Sakai, T., 2004, Successive determination of copper and iron by a flow injection-catalytic photometric method using a serial flow cell, Anal. Sci., 20 (1), 171-175.

[19] Al-Abachi, M.Q., Abed, S.S., and Al-Najjar, N.A., 2017, A new chromogenic reagent for determination of copper(II) in water samples using flow injectiontechnique, Iraqi J. Sci., 58 (1), 201-210.

[20] Satheesh, K.P., Ravichandran, S., and Rao, V.S., 2011, Spectrophotometric determination of $\mathrm{Cu}$ (II) and $\mathrm{Ni}$ (II) using 4-hydroxybenzaldehyde thiosemicarbazone, Int. J. ChemTech Res., 3 (4), 2062-2065.

[21] Ali, A.A.M., AL-Da'amy, M.A., and Kadhier, A.F., 2010, Synthesis of 2-[(3-chloro-4,6-disulfanamide phenyl) azo] -4,5-diphenyl imidazole (Cdsai) as a new analytical reagent for the determination of $\mathrm{Cu}(\mathrm{II})$, Iraqi Nat. J. Chem., 37, 66-73.

[22] Kadhim, S.H., Abd-Alla, I.Q., and Hashim T.J., 2017, Synthesis and characteristic study of Co(II), $\mathrm{Ni}$ (II) and $\mathrm{Cu}$ (II) complexes of new Schiff base derived from 4-aminoantipyrine, Int. J. Chem. Sci., 15 (1), 107-114.

[23] Aswar, A., Bansod, A.D., Aswale, S.R., and Mandlik, P.R., 2004, Synthesis, characterization, electrical and biological studies of $\mathrm{Cr}(\mathrm{III}), \mathrm{Mn}(\mathrm{III})$, $\mathrm{Fe}(\mathrm{III}), \mathrm{Ti}(\mathrm{III}), \quad \mathrm{VO}(\mathrm{IV}), \quad \mathrm{Th}(\mathrm{IV}), \quad \mathrm{Zr}(\mathrm{IV})$ and $\mathrm{UO}_{2}(\mathrm{VI})$ polychelates with bis-bidentate Schiff base, Indian J. Chem., 43A, 1892-1896.

[24] Reiss, A., Samide, A., Ciobanu, G., and Dăbuleanu, I., 2015, Synthesis, spectral characterization and thermal behavior of new metal(II) complexes with Schiff base derived from amoxicillin, J. Chil. Chem. Soc., 60 (3), 3074-3079.

[25] Funk, W., Dammann, V., Donnevert, G., Ianelli, S., Ianelli, E., and Gray, A., 2007, Quality Assurance in Analytical Chemistry: Applications in Environmental, Food, and Materials Analysis, Biotechnology, and Medical Engineering, $2^{\text {nd }} E d$. ., Wiley-VCH Verlag GmbH \& Co. KGaA, Weinheim, 35. 
[26] Tirmizi, S.A., Wattoo, M.H.S., Sarwar, S., Anwar, W., Wattoo, F.H., Memon, A.N., and Iqbal, J., 2009, Spectrophotometric study of stability constants of famotidine- $\mathrm{Cu}(\mathrm{II})$ complex at different temperatures, Arabian J. Sci. Eng., 34 (2), 43-48.

[27] Yousif, E., Adil, H., and Aziz, Y.F.A., 2010, Synthesis and characterization of some metal ions with 2-amino acetate benzothiazole, J. Appl. Sci. Res., 6 (7), 879-882.

[28] Skorik, N.A., Filippova, M.M., Bukhol'tseva, E.I., Mal'kov, V.S., and Kurzina, I.A., 2015, Russ. J. Inorg. Chem., 60 (6), 729-735.

[29] Mihelj, T., Tomašić, V., Biliškov, N., and Liu, F., 2014, Temperature-dependent IR spectroscopic and structural study of 18-crown- 6 chelating ligand in the complexation with sodium surfactant salts and potassium picrate, Spectrochim. Acta, Part A, 124, 12-20.

[30] Varga, G., Csendens, Z., Peintler, G., Berkesi, O., Sipos, P., and Palinko, I., 2014, Using low-frequency IR spectra for the unambiguous identification of metal ion-ligand coordination sites in purpose-built complexes, Spectrochim. Acta, Part A, 122, 257-259.

[31] Silverstein, R.M., Webster, F.X., and Kiemle, D., 1996, Spectrometric Identification of Organic Compound, $6^{\text {th }}$ Ed, John Wiley \& Sons, Inc., New York, 180.

[32] Al-Adilee, K.J., and Hesson, H.M., 2015, Synthesis, identification, structural, studies and biological activity of some transition metal complexes with novel heterocyclic azo-Schiff base ligand derived from benzimidazole, J. Chem. Pharm. Res., 7 (8), 89-103.

[33] Sugiyarto, K.H., Kusumawardani, C., and Wulandari, K.E., 2018, Synthesis and structural analysis of powder complex of tris(bipyridine) cobalt(II) trifluoromethanesulfonate octahydrate, Indones. J. Chem., 18 (4), 696-701.

[34] Al-Shareefi, A.N., Kadhim, S.H., and Jawad, W.A., 2013, Synthesis and study of Fe(III), Co(II), Ni(II) and $\mathrm{Cu}$ (II) complexes of new Schiffs base ligand derived from 4-amino antipyrine, J. Applicable Chem., 2 (3), 438-446. 